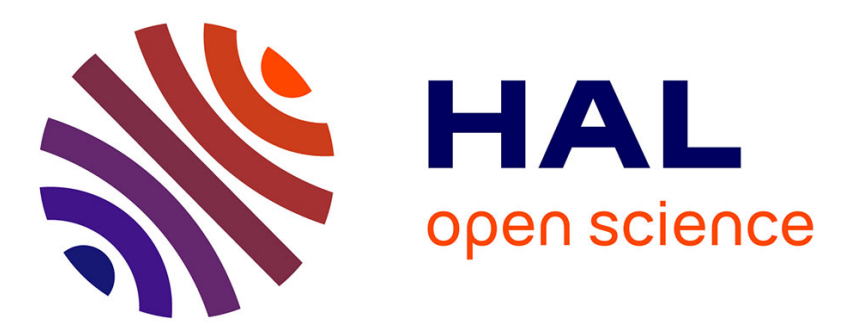

\title{
Food rejection in young children: Validation of the Child Food Rejection Scale in English and cross-cultural examination in the UK and France
}

Camille Rioux, Jérémie Lafraire, Delphine Picard, Jacueline Blissett

\section{- To cite this version:}

Camille Rioux, Jérémie Lafraire, Delphine Picard, Jacueline Blissett. Food rejection in young children: Validation of the Child Food Rejection Scale in English and cross-cultural examination in the UK and France. Food Quality and Preference, 2019, 73, pp.19-24. 10.1016/j.foodqual.2018.11.018 . hal02006244

\author{
HAL Id: hal-02006244 \\ https://hal.science/hal-02006244
}

Submitted on 4 Feb 2019

HAL is a multi-disciplinary open access archive for the deposit and dissemination of scientific research documents, whether they are published or not. The documents may come from teaching and research institutions in France or abroad, or from public or private research centers.
L'archive ouverte pluridisciplinaire HAL, est destinée au dépôt et à la diffusion de documents scientifiques de niveau recherche, publiés ou non, émanant des établissements d'enseignement et de recherche français ou étrangers, des laboratoires publics ou privés. 


\title{
Food rejection in young children: Validation of the Child Food Rejection Scale in English and cross-cultural examination in the UK and France
}

\author{
Camille Rioux $^{\mathrm{a}, \mathrm{b}, *}$, Jérémie Lafraire ${ }^{\mathrm{c}, 1}$, Delphine Picard ${ }^{\mathrm{b}, 2}$, Jacueline Blissett ${ }^{\mathrm{d}, 3}$ \\ ${ }^{a}$ Max Planck Research Group Naturalistic Social Cognition, Max Planck Institute for Human Development, Berlin, Germany \\ ${ }^{\mathrm{b}}$ Aix Marseille Université, PSYCLE EA3273, 13621 Aix en Provence, France \\ ${ }^{\mathrm{c}}$ Center for Food and Hospitality Research, Paul Bocuse Institute, Ecully, France \\ ${ }^{\mathrm{d}}$ Department of Psychology, School of Life and Health Sciences, Aston University, Birmingham, UK
}

A R T I C L E IN F O

\section{Keywords:}

Cultural differences

Food rejection

France

United Kingdom

Scale validation

\begin{abstract}
A B S T R A C T
Although there are numerous studies examining food rejection (neophobia and pickiness), very few studies have directly compared these particular behaviors in children from different countries. Testing children from different countries is important for future research, as there are clear differences between European countries in early feeding practices and child fruit and vegetable consumption. In the present study we aimed to (i) validate the Child Food Rejection Scale in English and (ii) compare children's food neophobia and pickiness in the UK and France. To that aim, the Child Food Rejection Scale was first translated into English and its reliability and validity were assessed. Second, food rejection scores in a UK sample $(n=117)$ and in a French sample $(n=256)$ were directly compared to examine cross-cultural differences. Results showed that the Child Food Rejection Scale can be successfully used outside France. Moreover results revealed that UK children are less neophobic and picky than French children. These cultural differences can be useful to inform targeted interventions to change food related behaviors in these different populations.
\end{abstract}

\section{Introduction}

Children's low consumption of fruits and vegetables is a common source of concern for parents who are worried about their child's dietary diversity (DeCosta, Möller, Fröst, Olsen, 2017). Consumption of adequate fruits and vegetables is needed for normal and healthy development (Woodside, Young, \& McKinley, 2013) and may protect against longer-term ill health (Astrup, Dyerberg, Selleck, \& Stender, 2008; Oyebode, Gordon-Dseagu, Walker, \& Mindell, 2014). There is a wide gap between recommended intake (i.e., five portions of fruits and vegetables a day, WHO, 2003) and actual consumption of fruits and vegetables (Cockroft, Durkin, Masding, \& Cade, 2005). For instance, in France, 3-to 17-year-old children eat an average of three portions of fruits and vegetables a day (Tavoularis \& Hebel, 2017) and in the UK, 4to 10-year-old children eat an average of only two portions a day (National Diet and Nutrition Survey, 2014). Nevertheless, while both UK and French consumption is below recommended intakes, from these studies it seems that French children tend to eat more fruits and vegetables than their UK counterparts. However the recent European project "HabEat", designed to compare feeding practices and eating behaviors in six European countries (https://www.habeat.eu), revealed a more mixed picture of the differences between UK and French children (Ahern et al., 2013; de Lauzon-Guillain et al., 2013; Jones et al., 2015; Oliveira et al., 2015). For example, Ahern et al. (2013), in a study of 6-to 36-month-old children, demonstrated that children from the UK had been introduced to more vegetables than French children. In another study, de Lauzon-Guillain et al. (2013) found that UK mothers tend to introduce solid food into children's diet earlier than their French counterparts. Understanding cultural differences in fruit and vegetable rejection motives can be useful to inform targeted interventions to change food related behaviors in these different populations (Blissett \& Bennett, 2013; Markovina et al., 2015; Musher-Eizenman, de LauzonGuillain, Holub, Leporc, \& Charles, 2009).

Food rejection, appearing in the second year of life, has been

\footnotetext{
*Corresponding author at: Max Planck Research Group Naturalistic Social Cognition, Max Planck Institute for Human Development, Lentzallee, 94, Berlin 14195, Germany.

E-mail address: rioux@mpib-berlin.mpg.de (C. Rioux).

${ }^{1}$ Present address: Center for Food and Hospitality Research, Paul Bocuse Institut, Chateau du Vivier BP 25, 69130 Ecully, France.

${ }^{2}$ Present address: Aix Marseille Université, Laboratoire PSYCLE EA3273, Maison de la recherche, 29 Avenue Schuman, 13621 Aix en Provence, France.

${ }^{3}$ Present address: Department of Psychology, School of Life and Health Sciences, Aston University, Birmingham B4 7ET, UK.
} 
presented as strong obstacle to improving children's intake of fruits and vegetables (Dovey, Staples, Gibson, \& Halford, 2008; Lafraire, Rioux, Giboreau, \& Picard, 2016). Indeed numerous studies revealed a robust and negative association between food rejection and intake of fruits and vegetables (e.g., Fletcher, Wright, Jones, Parkinson, \& Adamson, 2017; Perry et al., 2015). The notion of food rejection usually encompasses food neophobia and food pickiness (Dovey et al., 2008). Food neophobia is defined as the rejection of new foods before the tasting step (Pliner \& Hobden, 1992) and food pickiness as the restricted intake of familiar, as well as new foods, that can occur before and during the tasting step (Dovey et al., 2008; Taylor, Wernimont, Northstone, \& Emmett, 2015). Food pickiness can also be extended to include rejection of certain food textures (Taylor et al., 2015). Food neophobia and pickiness have been found to be two distinct, though correlated, dimensions of food rejection (Rigal, Chabanet, Issanchou, \& MonneryPatris, 2012; Rioux, Lafraire, \& Picard, 2017). Therefore it is important to compare both children's food neophobia and pickiness in France and the UK, to further understand cultural differences in vegetable consumption.

A handful of studies have compared food neophobia between different countries or cultures (e.g., de Wild et al., 2018; Olabi, Najm, Baghdadi, \& Morton, 2009; Ritchey, Frank, Hursti, Tuorila, 2003). For example, comparing American, Swedish and Finnish adults' neophobia, Ritchey et al. (2003) found that Swedish adults were less neophobic than their American and Finnish counterparts. However, we know very little about cultural differences in France and the UK in food neophobia in toddlerhood and preschool age. Furthermore, to our knowledge very few studies have yet directly examined cultural variations in picky eating (see de Wild et al., 2018, for comparison between Greece, Denmark and the Netherlands). A recent systematic review and metaanalysis of correlates of picky eating and neophobia in young children (Cole, An, Lee, \& Donovan, 2017) demonstrated that whilst there are a number of studies across the world examining picky eating and neophobia, few studies have compared these particular behaviors in children from different cultural groups. Testing children from different cultural groups is important for future research, as there are clear differences between European countries in early feeding practices and child fruit and vegetable consumption (revealed notably by the HabEat project, e.g., Ahern et al., 2013; de Lauzon-Guillain et al., 2013).

One of the barriers to comparison of children's behaviors between cultural groups is the lack of measures validated for each culture of interest. To compare food neophobia and pickiness in French and UK children, a scale validated in both cultures is needed (Ritchey, Frank, Hursti, \& Tuorila, 2003). In a recent review of methods to assess preschool children's eating behavior, de Lauzon-Guillain et al. (2012) pointed out that most of existing scales measuring children's food neophobia and/or pickiness are not entirely psychometrically sound (i.e., internal consistency, temporal reliability or construct validity are not assesed or achieved, de Lauzon-Guillain et al., 2012; Ritchey et al., 2003). Indeed, only the French Questionnaire pour Enfant de Neophobie Alimentaire (QENA, Rubio, Rigal, Boireau-Ducept, Mallet, \& Meyer, 2008) and the Children Eating Behavior Questionnaire (CEBQ, Wardle, Guthrie, Sanderson, \& Rapoport, 2001) achieved all validity and reliability criteria (other questionnaires such as the widely used Food Neophobia Scale and Children's Food Neophobia Scale developed by Pliner, failed to satisfy construct validity and/or temporal reliability). This is consistent with Damsbo-Svendsen, Fröst, and Olsen's review (2017) on instruments developed to measure food neophobia, that recommend using the CEBQ to measure eating behavior for children from the age of two. However, the QENA is a self-assessment questionnaire designed to measure neophobia for at least 5-year-old children, while it would be of interest to measure neophobia for children as young as 2 years of age since it is widely acknowledged that this is the onset of food neophobia (Dovey et al., 2008). On the other hand, the CEBQ does not differentiate between food neophobia and pickiness (de LauzonGuillain et al., 2012), and recent reviews and studies have proposed that they are two latent variables (Dovey et al., 2008; Galloway, Lee, \& Birch, 2003; Rigal et al., 2012). Very recently, in France, a scale to measure both neophobia and pickiness in 2-to 6-year-old children has been developed and validated: the Child Food Rejection Scale (CFRS) (Rioux et al., 2017). The CFRS is a bi-dimensional scale that comprises a total of 11 items; caregivers are asked to what extend they agree with 6 statements regarding their child's neophobia (dimension 1) (e.g. "My child always chooses familiar foods") and 5 statements regarding their child's pickiness (dimension 2) ("My child refuses certain foods due to their texture"). The CFRS represents an efficient and valuable tool for studying food rejection tendencies in young French children through their caregivers (Rioux et al., 2017); nevertheless it is currently available only in French.

The present study has therefore two goals: firstly, to explore the validity and reliability of the translated measure of the CFRS in a UK sample; and secondly, to compare children's food neophobia and pickiness across France and the UK. Because the literature has revealed mixed results about French and UK fruit and vegetable consumption, it was hypothesized that French and UK children would differ on their levels of food neophobia and pickiness; nevertheless, we did not have a prediction regarding the direction of the supposed cross-national differences. We also investigated whether the hypothesized difference was age dependent and was driven by any particular questionnaire item.

\section{Method}

\subsection{Translation of the CFRS}

The CFRS, which was initially developed and validated in France by Rioux et al. (2017), was first translated into English through a forward backward translation process, according to the recommended guidelines for scale translation (Hambelton, Meranda, \& Spielberger, 2005; Vallerand, 1989). (i) First, two bilingual speakers, whose first language was English, translated the original French CFRS into English. (ii) Two bilingual speakers, whose first language was French, then independently back translated the two preliminary English versions into French. These two new French versions were compared to identify discrepancies and negotiate an updated French version. (iii) The original French version and the updated French version were then compared to assure conformity. (iv) Finally, a sample of 19 bilingual speakers responded to the two versions (English and original French version) with a two-week interval. They were additionally asked to indicate whether the items were clear and correctly phrased. From their comments, the wording of the English version was slightly modified. The correlation between the score to the French original version and the final English version was high $(r=0.87, \mathrm{p}<0.0001)$. The two versions are presented in Table 1.

\subsection{Participants and procedure}

Two samples of caregivers ( $\mathrm{n}=256$ for French and $\mathrm{n}=117$ for UK) were included in the current study. French data were collected in spring 2015 (for a full account of which please refer to Rioux et al., 2017). UK data were collected in summer 2017, for the purpose of this study. The study was approved by the Ethics Committee of Coventry University (P52573) and parents gave online consent for their participation. Caregivers were recruited online through social media (Twitter, Facebook). An advert for the study with a link to further information about the study was circulated via these routes. Focusing recruitment on social media may result in a better educated, younger sample of participants, but online recruitment has the advantage of rapid recruitment in short time frames (Leonard, Hutchesson, Patterson, Chalmers, \& Collins, 2014). Parents filled the English CFRS for their child aged between 2 and 7 years. This age range was selected since food rejection behaviors occur at this age and seem relatively stable during this period (Addessi, Galloway, Visalberghi, \& Birch, 2005; Cooke, Wardle, \& 
Table 1

Original French version and (translated) English version of the CFRS.

\begin{tabular}{|c|c|}
\hline & Items \\
\hline \multirow[t]{12}{*}{ Neophobia subscale } & N1.Mon enfant recherche constamment des aliments familiers. \\
\hline & My child always chooses familiar food. \\
\hline & N2.Mon enfant se méfie des aliments nouveaux. \\
\hline & My child is suspicious of new foods. \\
\hline & N4.Mon enfant aime seulement la cuisine qu'il connaît. \\
\hline & My child likes the types of foods they know. \\
\hline & N6.Mon enfant rejette un nouvel aliment avant même de l'avoir goûté. \\
\hline & My child rejects new foods without even tasting them. \\
\hline & N7.Mon enfant est angoissé à la vue d'un nouvel aliment. \\
\hline & My child gets anxious when they see new foods. \\
\hline & N10.Mon enfant ne goûte pas un nouvel aliment si cet aliment est en contact avec un autre aliment qu'il n'aime pas. \\
\hline & My child won't taste a new food if it's been in contact with another food they don't like. \\
\hline \multirow[t]{10}{*}{ Pickiness subscale } & P3.Mon enfant refuse de manger certains aliments à cause de leurs textures. \\
\hline & My child refuses to eat some foods because of their texture. \\
\hline & P4.Mon enfant fait le tri dans son assiette. \\
\hline & My child separates the food on their plate. \\
\hline & P5.Mon enfant rejette certains aliments après les avoir goûté. \\
\hline & My child rejects some foods after tasting them. \\
\hline & P6.Mon enfant peut manger un aliment aujourd'hui et le refuser demain. \\
\hline & Sometimes, my child will eat a food one day and refuse it the next day. \\
\hline & P10.Mon enfant peut manger certains aliments en grandes quantités et d'autres pas du tout. \\
\hline & My child can eat some foods in large amounts and others not at all. \\
\hline
\end{tabular}

Note. The numbers of the items (N1, N2, N4, N7, N10, P3, P4, P5, P6 and P10) were kept from the original French CFRS (see Fig. 1 in Rioux et al., 2017).

Table 2

Demographic characteristics of the French and UK samples.

\begin{tabular}{lll}
\hline Variable & French & UK \\
\hline Sample size (n) & 256 & 117 \\
Children's age (months)-mean ( \pm SD) & $47( \pm 15)$ & $51( \pm 18)$ \\
Children's age (months)-range & $22-84$ & $23-83$ \\
Children's sex & $51 \%$ girls & $43 \%$ girls \\
\hline
\end{tabular}

Note. Children ages are not significantly different across the UK and FR sample $(\mathrm{t}=1.5, \mathrm{p}=0.12)$. Sex ratio is significantly different across the UK and FR sample $(\mathrm{chi}=24.9, \mathrm{p}=0.045)$.

Gibson, 2003; Dubois, Farmer, Girard, Peterson, \& Tatone-Tokuda, 2007; Koivisto-Hursti \& Sjoden, 1996; Nicklaus, Boggio, Chabanet, \& Issanchou, 2005; Rioux et al., 2017; Rioux, Lafraire, \& Picard, 2018; but see Cashdan, 1994, for opposite results). Parents of children not born in the UK $(n=20)$, or parents of children younger than 2 years $(n=3)$ were excluded from the study, leaving a sample of 117 English caregivers (mainly mothers). Details about the demographic characteristics of the French and UK samples can be found in Table 2.

Similarly to the procedure used in Rioux et al. (2017) for the French sample, English caregivers rated each item according to their child's behavior on a 5-point Likert-like scale (Strongly disagree, Disagree, Neither agree nor disagree, Agree, Strongly agree). Each answer was then numerically coded. For each child, three scores can be obtained: a food neophobia sub-score (range from 6 to 30), a food pickiness subscore (range from 5 to 25 ) and a (total) food rejection score (range from 11 to 55). As the original French CFRS does not contain any reversescored items (Rioux et al., 2017) the neophobia sub-score is obtained by simply summing the score for each neophobia item, and the same procedure is followed for the pickiness sub-score. The total food rejection score is obtained by summing the neophobia and pickiness subscores. High scores indicate high food rejection dispositions. UK caregivers were also asked to fill the Food Neophobia Scale (FNS, Pliner \& Hobden, 1992) for their child to enable to examine convergent validity of the new scale with an established measure of neophobia.

\subsection{Data analysis}

First, to test the validity of the translated CFRS in the UK sample, we assessed its construct validity, convergent validity and reliability. To assess its construct validity, we performed a confirmatory factorial analysis (CFA) to verify that the 2-factor model found for the original CFRS by Rioux et al. (2017) fit the English data. To determine how well the 2-factor model fit the English data, we focused on four fit indices: the $\frac{C h i^{2}}{d f}$, the Goodness-of-Fit Index (GFI), the Comparative Fit Index (CFI), and the Root Mean Square Error of Approximation (RMSEA) (Jackson, Gillaspy, \& Purc-Stephenson, 2009; Wheaton, Muthén, Alwin, \& Summers, 1977). To assess its convergent validity, we calculated the correlation between CFRS scores and FNS scores (Spearman's correlation coefficient). To assess its reliability, we measured its internal consistency with Cronbach's alpha coefficient.

Second, we examined cross-cultural differences in children's food neophobia and pickiness. To that end, in both populations, the mean food rejection scores for each sex were compared (Wilcoxon's test), and correlations between food rejection scores and children's age were assessed (Spearman correlation coefficient). In addition, differences between UK and French food rejection scores were analyzed by MannWhitney tests for independent samples. Non-parametric approach was chosen because of the non-normal distribution of the variables.

We set the alpha level at 0.05 for all statistical analyses. R 3.1.2 software (Crawley, 2007) and LISREL 9.10 (Jöreskog \& Sörbom, 2012) were used to conduct the statistical analyses.

\section{Results}

\subsection{Validity and reliability of the English CFRS}

The 2 -factor model extracted from the French sample (Model 1, see Table 3 and Fig. 1 in Rioux et al., 2017) was fitted to the UK sample. As shown in Table 3, the fit statistics for Model 1 revealed marginal fit, as indicated by the $\frac{\mathrm{Chi}^{2}}{d f}$, RMSEA, GFI and CFI values. Review of the items loading estimates revealed that items P3, P4 and N4, did not load on the expected dimensions for the UK data. These items were dropped and the model fit was re-estimated (Model 2, see Table 3). These modifications resulted in acceptable fit with improvement in all fit indices (see Table 3). The 8-item scale was then chosen for subsequent analyses in the UK sample.

Psychometric properties of the 8-item CFRS scale were then assessed in the UK sample. The 8-item English CFRS showed good convergent 
Table 3

Goodness of fit indices for the UK sample.

\begin{tabular}{|c|c|c|c|c|}
\hline & $\frac{C h i^{2}}{d f}$ & RMSEA & GFI & CFI \\
\hline $\begin{array}{l}\text { Model } 1 \text { (11 items) } \\
\text { Neophobia subscale: N1 N2 N4 N6 N7 N10 } \\
\text { Pickiness subscale: P3 P4 P5 P6 P10 }\end{array}$ & 1.86 & 0.09 & 0.88 & 0.94 \\
\hline $\begin{array}{l}\text { Model } 2 \text { (8 items) } \\
\text { Neophobia subscale: N1 N2 N6 N7 N10 } \\
\text { Pickiness subscale: P5 P6 P10 }\end{array}$ & 1.49 & 0.06 & 0.94 & 0.98 \\
\hline
\end{tabular}

Note. The required values for an acceptable fit are $\frac{\boldsymbol{C h} \boldsymbol{i}^{2}}{\boldsymbol{d f}}<3$, RMSEA $<0.05$, GFI > 0.9 and CFI > 0.9 (Jackon et al., 2009; Wheaton et al., 1977).

validity: the correlation between CFRS scores and FNS scores were highly correlated $(r=0.79, p<0.001)$. The 8-item English CFRS showed also good reliability as indicated by a Cronbach's alpha of 0.85 .

\subsection{Cultural differences in children's food rejection}

Variations in food rejection according to children's sex and age. Rioux et al. (2017) found that food rejection scores on the 11-item CFRS did not vary according to children's age or sex in the French sample. Comparatively, in the UK population, results from mean comparisons using a Wilcoxon test showed that boys and girls did not differ significantly on food rejection scores on the 8-item CFRS (W $=1664$, $n s$ ). We observed the same absence of sex effect for each subscale (both $p$ values were not significant). Secondly, correlation coefficients indicated that neither neophobia, pickiness nor total food rejection scores on the 8-item CFRS were significantly correlated with age in the UK sample (all $r<0.17, n s$ ).

UK-France differences in food rejection scores. Table 4 displayed mean food neophobia, mean pickiness and mean total food rejection scores to the 8-item scale in the UK sample and to the 11-item scale in the French sample. Because the two scales did not have the same number of items, to directly compare children from both countries, instead of adding the score for each question, we averaged them. Therefore, we have a value ranging from 1 to 5 (caregivers rated each item on a 5-point Likert-like scale) for the neophobia and pickiness subscales and for the total food rejection scale. Results from mean comparisons using Mann-Whitney's tests showed that UK children had significantly lower level of food rejection than French children (see Table 4). The same pattern was observed across subscales (see Table 4), and for most individual items (for P5-N6, UK children had lower values, for N6 and N10 UK children had higher values).

\section{Discussion}

In the present study, we aimed (i) to validate the CFRS for the UK population and (ii) to explore cultural differences between French and UK children in terms of food rejection.

Table 4

Food neophobia, pickiness and total rejection scores in UK and FR samples measured with the CFRS.

\begin{tabular}{llll}
\hline & UK & FR & Mann-Whitney's test \\
\hline Neophobia sub-scores & $2.5( \pm 1.1)$ & $2.9( \pm 1.0)$ & $p=0.012$ \\
Pickiness sub-scores & $1.6( \pm 0.8)$ & $3.7( \pm 0.8)$ & $p<0.0001$ \\
Total Food Rejection scores & $2.1( \pm 0.9)$ & $3.3( \pm 0.8)$ & $p<0.0001$
\end{tabular}

Note. Values are means \pm SD. For the UK sample the 8-item CFRS is used, for the French sample the 11-item CFRS is used. P values for mean comparisons using Mann-Whitney's tests are showed.

\subsection{Validation of the CFRS in the UK population}

The results reveal that the CFRS can be used outside France with UK preschoolers, with an 8-item modified version. The results indicated adequate psychometric properties of the UK version of the 8-item CFRS. Factor analysis supported the two-dimensional structure of the scale (namely the distinction between food neophobia and pickiness) as found in the original CFRS (Rioux et al., 2017). This is consistent with existing literature on food rejection in UK children, which distinguish between food neophobia and pickiness (e.g., Potts \& Wardle, 1998). Reliability, as measured through internal consistency, and convergent validity, were satisfactory with coefficients comparable to those found in previous research on children's food rejection (e.g., Raudenbush, Van der Klaauw, \& Frank, 1995; Rigal et al., 2012; Wardle et al., 2001).

Overall the findings provide support for the reliability and validity of the 8-item CFRS for UK children. It is interesting to note that, after cross-cultural adaptation and validation, a decrease in the number of relevant items is not rare (e.g., Laureati, Bergamaschi, \& Pagliarini, 2015; Picard \& Blanc, 2013; Ritchey et al., 2003). Nevertheless, we acknowledge that this study lacks of a test of temporal stability. An additional next step would also be to demonstrate that UK children with high CFRS scores would respond more negatively to new food stimuli than UK children with low CFRS scores.

\subsection{Cross cultural differences in food rejection}

Concerning the developmental path of food neophobia and pickiness and their possible variation across sex, result from the French and UK samples are convergent. In both sample, CFRS scores did not vary according to age or sex. Regarding food rejection variation across countries, as expected French and UK children differed on their levels of food neophobia and pickiness. French children had both higher levels of food neophobia and pickiness than UK children (although the difference for pickiness was more important and concerned all the items of that sub-scale), a finding in line with evidence showing a narrower fruit and vegetable repertoire in 1-to 5-year-old French children (Ahern et al., 2013; Jones et al., 2015; Oliveira et al., 2015). It would be interesting to examine potential change in this pattern in older children since evidence has revealed a higher fruit and vegetable consumption in the French population for the older population (National Diet and Nutrition Survey, 2014; Tavoularis \& Hebel, 2017). Several explanations can account for the higher food neophobia and pickiness in our French sample. First, it is possible that our findings may reflect differences in socially desirable responding rather than objective differences between cultural groups (Blissett \& Bennett, 2013). It is indeed possible that UK caregivers are more prone than French caregivers to present a better image of their children. Proposing a behavioral food rejection task to UK preschoolers and test whether the behaviors to this task correlate to CFRS scores would allow checking for potential differences in social desirability bias. Second, the findings may also reflect differences in the socio-economic status of the caregivers in the French and UK samples. In the UK sample caregivers came principally from white Caucasian communities and had diverse education level (e.g. 46\% caregivers completed a postgraduate degree, and $33 \%$ completed a undergraduate degree). A limitation of the present study is that we did not collect demographic information for our French sample. Therefore we cannot be confident that the differences revealed in the present study are not partly due to sampling effects. Nevertheless, in their recent review of correlates of food neophobia and pickiness, Cole and colleagues (2017) showed that null findings were reported in general for the association between socio-economic status and pickiness and neophobia (Carruth, Ziegler, Gordon, \& Barr, 2004; Cassells, Magarey, Daniels, \& Mallan, 2014; Hendricks, Briefel, Novak, \& Ziegler, 2006). Finally, the differences found in CFRS scores between the two samples may also reflect differences in food rejection per se. Cole et al. (2017) and Lafraire et al. (2016), in their respective review of food neophobia and pickiness, 
presented a typology of factors modulating or correlating with these two kinds of food rejection behaviors. For instance, it is well recognized that food exposure during infancy decreases food rejection behaviors (e.g., Laureati, Bergamaschi, \& Pagliarini, 2014; Rioux et al., 2018; see Cooke, 2007, Heath, Houston-Price, \& Kennedy, 2011 for reviews). Given the evidence that UK caregivers present more vegetables, and more often, to their 6- to 36-month-old-children, compared to French caregivers (Ahern et al., 2013), it is plausible that the difference in food rejection between UK and French preschoolers arises partly from this difference in food exposure in early life. Moreover, one study of the project HabEat also revealed that UK mothers tend to introduce solid food into children's diet earlier than their French counterparts (de Lauzon-Guillain et al., 2013), while a longitudinal study revealed that introducing solid foods before age 6 months was associated with less picky eating later in life (Northstone et al., 2000, but see Brown \& Lee, 2015 for the opposite pattern). This cultural difference in weaning practices may also partly explain the differences in CFRS scores revealed in the present study. This is possible since the observed crossnational differences we found were mainly due to pickiness and one of the important characteristics of pickiness is rejection of certain textures. Such a rejection may be reduced with earlier introduction to solid foods, facilitating a wider acceptance of textures.

\subsection{Implication for future health interventions}

Understanding cultural differences in fruit and vegetable rejection motives can be useful to inform targeted interventions to change food behaviors in these different populations (Blissett \& Bennett, 2013). The validation of the Child Food Rejection Scale in the UK population we conducted in the present study allowed the comparison of the French and UK population. This comparison revealed that 2-to 7-year-old French children are more neophobic and picky than their UK counterparts. In France nutrition campaigns could then target a reduction of food neophobia and pickiness in order to increase fruit and vegetable consumption. These two kinds of food rejection can be significantly decrease through food exposure, through an improvement of the conceptual apparatus of young children (Cooke, 2007; Heath et al., 2011; Rioux et al., 2018), and in France mother tend to not present enough fruits and vegetables to children (Ahern et al., 2013). Then, exposure campaigns in kindergarten canteens where the majority of children eat their week-day lunch (Czernichow \& Martin, 2000) could be an efficient way to decrease food rejection and hence increase fruits and vegetable consumption.

In the United Kingdom, since children present lower food neophobia and pickiness, nutrition campaigns could target other factors preventing fruit and vegetable consumption. A recent study reviewed the strategies used to change children's eating behavior (DeCosta, Møller, Frøst, \& Olsen, 2017). This review reveals that the degree to which fruits and vegetables are accessible to children (presented in a place and form that facilitate their consumption, e.g. pre-sliced at locations easily accessed by children, free of charge in canteens etc.) is strongly associated with their consumption (e.g., Bica \& Jamelske, 2012; Swanson, Branscum, \& Nakayima, 2009). Moreover, the review shows that choice architecture (Thaler \& Sunstein, 2009) has been shown to positively increase fruit and vegetable consumption (e.g., Courchesne, Ahrensbarbeau, \& Barnes, 2012; Schwartz, 2007). These types of intervention could potentially be more successful in improving fruit and vegetable consumption in the UK population.

\section{Acknowledgements}

The authors would like to acknowledge the parents for their helpful collaboration. We would also like to thank Vivian Fong who helped with data collection in the UK and the financial support from the Fondation Daniel and Nina Carasso for the data collection in France.

\section{References}

Addessi, E., Galloway, A. T., Visalberghi, E., \& Birch, L. L. (2005). Specific social influences on the acceptance of novel foods in 2-5-year-old children. Appetite, 45(3), 264-271. https://doi.org/10.1016/j.appet.2005.07.007.

Ahern, S. M., Caton, S. J., Bouhlal, S., Hausner, H., Olsen, A., Nicklaus, S., .. Hetherington, M. M. (2013). Eating a Rainbow. Introducing vegetables in the first years of life in 3 European countries. Appetite, 71, 48-56. https://doi.org/10.1016/j. appet.2013.07.005.

Astrup, A., Dyerberg, J., Selleck, M., \& Stender, S. (2008). Nutrition transition and its relationship to the development of obesity and related chronic diseases. Obesity Reviews, 9(Suppl 1), 48-52. https://doi.org/10.1111/j.1467-789X.2007.00438.x.

Bica, L. A., \& Jamelske, E. M. (2012). USDA fresh fruit and vegetable program creates positive change in children's consumption and other behaviors related to eating fruit and vegetables. Journal of Child Nutrition \& Management, 36(2).

Blissett, J., \& Bennett, C. (2013). Cultural differences in parental feeding practices and children's eating behaviours and their relationships with child BMI: A comparison of Black Afro-Caribbean, White British and White German samples. European Journal of Clinical Nutrition, 67(2), 180-184. https://doi.org/10.1038/ejcn.2012.198.

Brown, A., \& Lee, M. D. (2015). Early influences on child satiety-responsiveness: The role of weaningstyle. Pediatric Obesity, 10, 57-66. https://doi.org/10.1111/j.2047-6310. 2013.00207.x.

Carruth, B. R., Ziegler, P. J., Gordon, A., \& Barr, S. I. (2004). Prevalence of picky eaters among infants and toddlers and their caregivers' decisions about offering a new food. Journal of the American Dietetic Association, 104, 57-64. https://doi.org/10.1016/j. jada.2003.10.024.

Cashdan, E. (1994). A sensitive period for learning. Human Nature, 5(3), 279-291. https://doi.org/10.1007/BF02692155.

Cassells, E. L., Magarey, A. M., Daniels, L. A., \& Mallan, K. M. (2014). The influence of maternal infant feed-ing practices and beliefs on the expression of food neophobia in toddlers. Appetite, 82, 36-42. https://doi.org/10.1016/j.appet.2014.07.001.

Cockroft, J. E., Durkin, M., Masding, C., \& Cade, J. E. (2005). Fruit and vegetable intakes in a sample of pre-school children participating in the "five for all" project in Bradford. Public Health Nutrition, 8, 861-869. https://doi.org/10.1079/PHN2005734.

Cole, N. C., An, R., Lee, S. Y., \& Donovan, S. M. (2017). Correlates of picky eating and food neophobia in young children: A systematic review and meta-analysis. Nutrition Reviews, 75(7), 516-532. https://doi.org/10.1093/nutrit/nux024.

Cooke, L. (2007). The importance of exposure for healthy eating in childhood: A review. Journal of Human Nutrition and Dietetics, 20(4), 294-301. https://doi.org/10.1111/j. 1365-277X.2007.00804.x.

Cooke, L., Wardle, J., \& Gibson, E. J. (2003). Relationship between parental report of food neophobia and everyday food consumption in 2-6-year-old children. Appetite, 41(2), 205-206. https://doi.org/10.1016/S0195-6663(03)00048-5.

Courchesne, E., Ahrens-barbeau, C., \& Barnes, C. C. (2012). Photographs in lunch tray compartments and vegetable consumption among children in elementary school cafeterias. 307(8), 2012-2013.

Crawley, M. (2007). The R book. Whiley Publishing.

Czernichow, S., \& Martin, A. (2000). Nutrition et restauration scolaire, de la maternelle au lycée: Etat des lieux. ANSES, 1-36.

Damsbo-Svendsen, M., Frøst, M. B., \& Olsen, A. (2017). A review of instruments developed to measure food neophobia. Appetite, 113, 358-367. https://doi.org/10.1016/j appet.2017.02.032.

de Lauzon-Guillain, B., Jones, L., Oliveira, A., Moschonis, G., Betoko, A., Lopes, C., ... Charles, M. A. (2013). The influence of early feeding practices on fruit and vegetable intake among preschool children in 4 European birth cohorts. The American Journal of Clinical Nutrition, 98(3), 804-812. https://doi.org/10.3945/ajen.112.057026.

de Lauzon-Guillain, B., Oliveira, A., Charles, M. A., Grammatikaki, E., Jones, L., Rigal, N., et al. (2012). A review of methods to assess parental feeding practices and preschool children's eating behavior: The need for further development of tools. Journal of the Academy of Nutrition and Dietetics, 112(10), 1578-1602. https://doi.org/10.1016/j. jand.2021.06.356.

de Wild, V. W. T., Jager, G., Olsen, A., Costarelli, V., Boer, E., \& Zeinstra, G. G. (2018) Breast-feeding duration and child eating characteristics in relation to later vegetable intake in 2-6-year-old children in ten studies throughout Europe. Public Health Nutrition, 21, 2320-2323. https://doi.org/10.1017/S1368980018000769.

DeCosta, P., Møller, P., Frøst, M. B., \& Olsen, A. (2017). Changing children's eating behaviour - A review of experimental research. Appetite, 113, 327-357. https://doi.org/ 10.1016/j.appet.2017.03.004.

Dovey, T. M., Staples, P. A., Gibson, E. L., \& Halford, J. C. G. (2008). Food neophobia and 'picky/fussy' eating in children: A review. Appetite, 50(2-3), 181-193. https://doi. org/10.1016/j.appet.2007.09.009.

Dubois, L., Farmer, A., Girard, M., Peterson, K., \& Tatone-Tokuda, F. (2007). Problem eating behaviors related to social factors and body weight in preschool children: A longitudinal study. International Journal of Behavioral Nutrition and Physical Activity, 1, 4-9. https://doi.org/10.1186/1479-5868-4-9.

Fletcher, S., Wright, C., Jones, A., Parkinson, K., \& Adamson, A. (2017). Tracking of toddler fruit and vegetable preferences to intake and adiposity later in childhood. Maternal Child Nutrition, 13(2), https://doi.org/10.1111/mcn.12290.

Galloway, A. T., Lee, Y., \& Birch, L. L. (2003). Predictors and consequences of food neophobia and pickiness in young girls. Journal of the American Dietetic Association, 103(6), 692-698. https://doi.org/10.1053/jada.2003.50134.

Hambleton, R. K. (2005). Issues, designs, and technical guidelines for adapting tests into multiple languages and cultures. In R. K. Hambleton, P. F. Merenda, \& C. D. Spielberger (Eds.). Adapting educational and psychological tests for cross-cultural assessment (pp. 3-38). Mahwah, New Jersey: LEA. 
Heath, P., Houston-Price, C., \& Kennedy, O. B. (2011). Increasing food familiarity without the tears. A role for visual exposure? Appetite, 57(3), 832-838. https://doi.org/10. 1016/j.appet.2011.05.315.

Hendricks, K., Briefel, R., Novak, T., \& Ziegler (2006). Maternal and child characteristics associated with infant and toddler feeding practices. Journal of the American Dietetic Association, 106(S1), 135-148. https://doi.org/10.1016/j.jada.2005.09.035.

Jackson, D. L., Gillaspy, J. A., \& Purc-Stephenson, R. (2009). Reporting practices in confirmatory factor analysis: An overview and some recommendations. Psychological Methods, 14, 6-23. https://doi.org/10.1037/a0014694.

Jones, L., Moschonis, G., Oliveira, A., de Lauzon-Guillain, B., Manios, Y., Xepapadaki, P., et al. (2015). The influence of early feeding practices on healthy diet variety score among pre-school children in four European birth cohorts. Public Health Nutrition, 18(10), 1774-1784. https://doi.org/10.1017/S1368980014002390.

Jöreskog, K. G., \& Sörbom, D. (2012). LISREL 9.10. Chicago, IL: Scientific Software International.

Koivisto-Hursti, U.-K., \& Sjöden, P. (1996). Food and general neophobia in Swedish families: Parent-child comparisons and relationships with serving specific foods. Appetite, 26, 107-118. https://doi.org/10.1006/appe.1997.0108.

Lafraire, J., Rioux, C., Giboreau, A., \& Picard, D. (2016). Food rejections in children: Cognitive and social/environmental factors involved in food neophobia and picky/ fussy eating behavior. Appetite, 96, 347-357. https://doi.org/10.1016/j.appet.2015 09.008 .

Laureati, M., Bergamaschi, V., \& Pagliarini, E. (2014). School-based intervention with children. Peer-modeling, reward and repeated exposure reduce food neophobia and increase liking of fruits and vegetables. Appetite, 83, 26-32. https://doi.org/10.1016/ j.appet.2014.07.031.

Laureati, M., Bergamaschi, V., \& Pagliarini, E. (2015). Assessing childhood food neophobia: Validation of a scale in Italian primary school children. Food Quality and Preference, 40, 8-15. https://doi.org/10.1016/j.foodqual.2014.08.003.

Leonard, A., Hutchesson, M., Patterson, A., Chalmers, K., \& Collins, C. (2014). Recruitment and retention of young women into nutrition research studies: Practical considerations. Trials, 15, 23. https://doi.org/10.1186/1745-6215-15-23.

Markovina, J., Stewart-Knox, B. J., Rankin, A., Gibney, M., de Almeida, M. D. V., Fischer, A., ... Frewer, L. J. (2015). Food4Me study: Validity and reliability of Food Choice Questionnaire in 9 European countries. Food Quality and Preference, 45, 26-32. https://doi.org/10.1016/j.foodqual.2015.05.002.

Musher-Eizenman, D. R., de Lauzon-Guillain, B., Holub, S. C., Leporc, E., \& Charles, M. A. (2009). Child and parent characteristics related to parental feeding practices. A crosscultural examination in the US and France. Appetite, 52(1), 89-95. https://doi.org/ 10.1016/j.appet.2008.08.007.

National Diet and Nutrition Survey (2014). https://www.gov.uk/government/collections/national-diet-and-nutrition-survey (visited the 30/04/2018).

Nicklaus, S., Boggio, V., Chabanet, C., \& Issanchou, S. (2005). A prospective study of food variety seeking in childhood, adolescence and early adult life. Appetite, 44(3), 289-297. https://doi.org/10.1016/j.appet.2005.01.006.

Northstone, K., Emmett, P., Nethersole, F., et al. (2000). The effect of age of introduction to lumpy solids on foods eaten and reported feeding difficulties at 6 and 15 months. Journal of Human Nutrition and Dietetics, 14(1), 43-54.

Olabi, A., Najm, N. E. O., Baghdadi, O. K., \& Morton, J. M. (2009). Food neophobia levels of Lebanese and American college students. Food Quality and Preference, 20(5), 353-362. https://doi.org/10.1016/j.foodqual.2009.01.005.

Oliveira, A., Jones, L., de Lauzon-Guillain, B., Emmett, P., Moreira, P., Charles, M. A., \& Lopes, C. (2015). Early problematic eating behaviours are associated with lower fruit and vegetable intake and less dietary variety at 4-5 years of age. A prospective analysis of three European birth cohorts. British Journal of Nutrition, 114(05), 763-771. https://doi.org/10.1017/S0007114515002287.

Oyebode, O., Gordon-Dseagu, V., Walker, A., \& Mindell, J. S. (2014). Fruit and vegetable consumption and all-cause, cancer and CVD mortality: Analysis of Health Survey for England data. Journal of Epidemiology Community Health, 68(9), 856-862. https://doi. org/10.1136/jech-2013-203500.

Perry, R. A., Mallan, K. M., Koo, J., Mauch, C. E., Daniels, L. A., \& Magarey, A. M. (2015). Food neophobia and its association with diet quality and weight in children aged 24 months: A cross sectional study. International Journal of Behavioral Nutrition and Physical Activity, 12(13), https://doi.org/10.1186/s12966-015-0184-6.

Picard, D., \& Blanc, N. (2013). Need for humor scale: Validation with French children Psychological Reports, 112(2), 502-518. https://doi.org/10.2466/08.07.PR0.112.2. 502-518.

Pliner, P., \& Hobden, K. (1992). Development of a scale to measure the trait of food neophobia in humans. Appetite, 19(2), 105-120. https://doi.org/10.1016/01956663(92)90014-W.

Potts, H. W. W., \& Wardle, J. (1998). The list heuristic for studying personality correlate of food choice behaviour: A review and results from two samples. Appetite, 30(1), 79-92. https://doi.org/10.1006/appe.1997.0087.

Raudenbush, B., van der Klaauw, N. J., \& Frank, R. A. (1995). The contribution of psychological and sensory factors to food preference patterns as measured by the Food Attitudes Survey (FAS). Appetite, 25(1), 1-15. https://doi.org/ 10.1006/appe.1995. 0037.

Rigal, N., Chabanet, C., Issanchou, S., \& Monnery-Patris, S. (2012). Links between maternal feeding practices and children's eating difficulties. Validation of French tools. Appetite, 58(2), 629-637. https://doi.org/10.1016/j.appet.2011.12.016.

Rioux, C., Lafraire, J., \& Picard, D. (2017). The Child Food Rejection Scale: Developmen and validation of a new scale to assess food neophobia and pickiness among 2- to 7 year-old French children. Revue Européenne de Psychologie Appliquée/European Review of Applied Psychology, 67(2), 67-77. https://doi.org/10.1016/j.erap.2017.01.003.

Rioux, Camille, Lafraire, J., \& Picard, D. (2018). Visual exposure and categorization performance positively influence 3- to 6-year-old children's willingness to taste unfamiliar vegetables. Appetite, 120, 32-42. https://doi.org/10.1016/j.appet.2017.08. 016.

Ritchey, P. N., Frank, R. A., Hursti, U.-K., \& Tuorila, H. (2003). Validation and crossnational comparison of the food neophobia scale (FNS) using confirmatory factor analysis. Appetite, 40(2), 163-173. https://doi.org/10.1016/S0195-6663(02) 00134-4.

Rubio, B., Rigal, N., Boireau-Ducept, N., Mallet, P., \& Meyer, T. (2008). Measuring willingness to try new foods: A self-report questionnaire for French-speaking children. Appetite, 50(2-3), 408-414. https://doi.org/10.1016/j.appet.2007.09.012.

Schwartz, M. B. (2007). The influence of a verbal prompt on school lunch fruit consumption: A pilot study. International Journal of Behavioral Nutrition and Physical Activity, 4(1), 6. https://doi.org/10.1186/1479-5868-4-6.

Swanson, M., Branscum, A., \& Nakayima, P. J. (2009). Promoting consumption of fruit in elementary school cafeterias. The effects of slicing apples and oranges. Appetite, 53(2), 264-267. doi: 10.1016/j.appet.2009.07.015.

Tavoularis, G, \& Hebel, H. (2017). Fruits et légumes: les Français suivent de moins en moins la recommandation. Credoc, 292

Taylor, C. M., Wernimont, S. M., Northstone, K., \& Emmett, P. M. (2015). Picky/fussy eating in children: Review of definitions, assessment, prevalence and dietary intakes. Appetite, 95, 349-359.https. https://doi.org/10.1016/j.appet.2015.07.026.

Thaler, R. H., \& Sunstein, C. R. (2009). Nudge: Improving decisions about health, wealth, and happines. Penguin Books.

Vallerand, R. J. (1989). Vers une méthodologie de validation trans-culturelle de questionnaires psychologiques: Implication pour la recherche en langue française. Canadian Psychology, 30(4), 662-680. https://doi.org/10.1037/h0079856.

Wardle, J., Guthrie, C. A., Sanderson, S., \& Rapoport, L. (2001). Development of the children's eating behaviour questionnaire. Journal of Child Psychology and Psychiatry, 42(7), 963-970. https://doi.org/10.1111/1469-7610.00792.

Wheaton, B., Muthén, B., Alwin, D. F., \& Summers, G. F. (1977). Assessing reliability and stability in panel models. In D. Heise (Ed.), Sociological methodology (pp. 84-136). San Francisco, CA: Jossey-Bass. https://doi.org/10.2307/270754.

WHO (2003). Diet, nutrition, and the prevention of chronic diseases: Report of a WHOFAO expert consultation. WHO technical Report Series, 916. Geneva: World Health Organization.

Woodside, J. V., Young, I. S., \& McKinley, M. C. (2013). Fruits and vegetables: Measuring intake and encouraging increased consumption. The Proceedings of the Nutrition Society, 7(2), 236-245. https://doi.org/10.1017/S0029665112003059. 